\section{Desinfektion in der Geburtshilfe und manuelle Plazentarlösung.} Bemerkungen zu der Arbeit von C. Sievert in Nr. 23 dieser Wochenschrift.

Von Dr. Friedrich Gaus, praktischem Arzt in Bünde (Westfalen).

Verschiedene Schlußfolgerungen und Behauptungen von Sievert kann ich nicht unwidersprochen lassen, zumal er auch die Tätigkeit und Erfolge der praktischen Aerzte zum Vergleich seiner Resultate heranzieht.

$\mathrm{Ob}$ sich die neue Vorschrift des neuen Hebanmenlehrbuches, die Schamhaare der Kreißenden mit der Schere zu kürzen, in der allgemeinen Praxis einbürgern wird, wage ich sehr zu bezweifeln; stoßen wir schon häufig vor Operationen im Krankenhause auf energischen Widerspruch der zu Operierenden, um so mehr draußen im Privathause bei ungebildeten Leuten. Ich glaube nicht, daß die Hebamme einen Zwang ausüben kann. Rein sachlich halte ich natürlich die Vorschrift für sehr richtig.

Nun aber zu Sieverts Bemerkungen über den Gummihandschuh. Das eine ist doch jedenfalls unbestritten: der unverletzte, sterilisierte Gummihandschuh bildet einen vollkommenen aseptischen Ueberzug der Hand. Ich mag meine Hand noch so sehr desinfizieren, nie bin ich sicher, daß sie keimfrei ist. Im Krankenhause liegen natürlich die Verhältnisse günstiger, weil gerade der Anstaltsarzt weit mehr Berïhrung mit verdächtigem Material vermeiden kann. Der praktische Arzt ist dessen nie sicher, wenn er auch jede Berührung eiternder Wunden etc. vermeiden sollte. Ziehe ich über meine, nach den gebräuchlichen Vorschriften (Für bringer oder dergleichen) gereinigte Hand meinen ausgekochten Gummihandschuh, so weiß ich positiv, daß von meiner Hand keine Keime in die Genitalien der Kreißenden gelangen können. Das ist namentlich bei folgendem Wochenbettfieber sehr beruhigend. In bezug auf das Emporstreifen von Keimen, die der Kreißenden anhaften, verhält sich die gummibehandschuhte Hand noch weit günstiger als die unbekleidete, das wird jeder sofort zugeben, der einmal gefühlt hat, wie glatt erstere Hand eingeht im Vergleich zur bloßen Hand. Selbst unsere einfachen Frauen auf dem Lande wissen das schon, solche, bei denen inehrfach Wendungen gemacht sind, empfinden die Wendung mit dem Gummihandschuh (speziell das meist schmerzhafte Eingehen der Hand durch die Schamspalte) als weit schonender.

Natürlich muß man seines Handschuhs sicher sein. Das kann man aber heute bei der verbesserten Herstellungsweise. Ich benutze seit zehn Monaten ein und dasselbe Paar Handschuhe (dickere Qualität) bei etwa 150 Entbindungen, vor denen jedesmal die Handschuhe einfach im Kochtopf mit oder ohne Instrumente (Zange etc.) gekocht wurden, ohne daß auch nur ein einziger winziger Defekt vorhanden ist. Mehr kann man nicht verlangen. Ich bin fest überzeugt, daß die Wochenbettsmorbidität der geburtshilflichen Allgemeinpraxis geringer sein würde, wenn alle Aerzte beim Eingehen der Hand in die Genitalien der Kreißenden den sterilen Gummihandschuh benutzten.

Nun zu den Ausführungen über manuelle Plazentarlösungen. Ich weiß nicht, auf Grund welcher Erhebungen $\mathrm{Bu} \mathrm{m} \mathrm{m}$ und Runge eine Mortalität der manuellen Plazentarlösung durch praktische Aerzte von $10 \%$ und $11 \%$ berechnet haben.

Ich habe auf etwa 1500 Entbindungen (fast nur pathologische, da normale fast ausschließlich von Hebammen geleitet) in zehn Jahren rund 160 manuelle Plazentarlösungen gemacht und von letzteren keine einzige verloren, also eine
Mortalität von $0 \%$. Die Gesamtmortalität der Entbindungen betrug $2=0,13 \%$, ein Fall an Eklampsie, der zweite an puerperaler Sepsis (einfache Zange). Dabei ist nicht zu vergessen, daß wir in der Allgemeinpraxis häufig erst zur manuellen Plazentarlösung gerufen werden, wenn die Hebamme nach großem Blutverlust die Plazenta nicht exprimieren kann. Unsere Fälle sind also mit denen der Anstaltspraxis garnicht, höchstens mit denen der Poliklinik zu vergleichen. Ich bin nicht so vermessen, anzunehmen, daß meine Mortalität der manuellen Plazentarlösungen vereinzelt dasteht, ein Kollege, den ich darum befragte, erinnert sich auch nicht, in langen Jahren einen Fall an manueller Plazentarlösung verloren zu haben, ausgenommen einige wenige Fälle, die schon moribund zur Behandlung kamen.

Ich möchte also als Schluß folgende Sätze aufstellen: 1. Die Einführung des Gummihandschuhs in die allgemeine geburtshilfliche Praxis bedentet einen großen Sicherheitskoëffizienten gegen puerperale Infektionen seitens des Arztes.

2. Die Mortalität der manuellen Plazentarlösung in der Allgemeinpraxis ist nicht immer höher als in der Anstaltspraxis. 